\title{
BUDAYA BERBALAS PANTUN DALAM ACARA ADAT ISTIADAT PERKAWINAN MELAYU SAMBAS
}

\author{
Aslan, Ari Yunaldi \\ Institut Agama Islam Sultan Muhammad Syafiuddin Sambas \\ email korespondensi: aslanmarani88@yahoo.com, ariyunaldi34@gmail.com2
}

Received: ; Accepted : ;Published :

\begin{abstract}
The pantunis an old poetry category that has not been found who created it yet. Long ago until now, the pantun is usually used by the Malayan in various ceremonies and becomes their main identity. For the Sambas Malay, the pantun is not only a tradition but also as a marriage custom to deliver message to the couple in household life. From the result of literature research and writer's experience that run into the rite of marriage costum held by the Sambas Malay, it got some findings. First, the pantun describes the identity of Malayan. Second, in ancient times, the pantun had a golden system, so that many western anthropologists who researched the pantun from the Malayan in Indonesia. Third, in marriage costum held by the Malayan, the pantun's requited culture is still applied today. However, for both man and woman prepare the oldster to reciprocate the pantun each other when the wedding is held. A worrying thing to the writer, only the old people who can do the pantun's requited culture, while the young people do not learn until the time comes, the pantun is only a symbol that has been forgotten by the Malayan nowadays.
\end{abstract}

Keywords: Pantun, Melayu Sambas, Perkawinan

Pantun merupakan syair yang tidak dikenal oleh siapapun yang telah membuatnya, tetapi dengan pantun dapat menggambarkan identitas masyarakat secara keseluruhan. Pantun merupakan simbol dalam berkomunikasi yang tidak terlepas dalam kehidupan masyarakat. Simbol dalam pantun digunakan sebagai media dalam berkomunikasi, yang secara historisnya tidak terlepas dari Suku Melayu, yang tinggal diberbagai daerah, misalnya di Indonesia, Brunei, Malaysia, Pattani, Riau, Singapura, Filipina Selatan dan di daerah-daerah lainnya. Pantun walaupun sudah dilupakan, bahkan hampir hilang dari suku Melayu yang disebabkan oleh perkembangan zaman yang begitu drastis, tetapi berbeda halnya y ang terjadi pada Suku Melayu yang ada di Sambas yang masih menggunakan pantun dengan berbalas pantun dalam adat istiadat perkawinan. Nilai-nilai dari pantun tersebut tidak terlepas dari budaya nenek moyang yang merupakan 
dari kearifan lokal itu sendiri yang berupa pepatah, petitih, norma-norma, kesan dan pesan yang telah menjadi budaya yang tidak pernah lekang dimakan oleh waktu.

Aslan, dalam penelitiannya menyebutkan bahwa meskipun sebagian kearifan lokal sudah hampir mulai hilang popularitasnya, tetapi pantun selalu mewarnai keemasan dari corak kehidupan Suku Melayu Sambas teutama dalam adat istiadat perkawinan. Lebih-lebih lagi, pantun bukan saja menjadi tradisi dari Suku Melayu, tetapi dalam acara perkawinan, pantun mengajarkan kepada pasangan yang baru menikah untuk memulai hidup baru dengan cara berbalas pantun antara pihak lelaki dan pihak perempuan. Adanya balasan pantun tersebut, yang dilakukan oleh kedua mempelai yang diutus oleh pihak laki-laki dan disambut oleh pihak perempuan telah tersirat pesan dan kesan moral yang nantinya menjadi bekal oleh pengantin untuk menciptakan keluarga sakinah, mawaddah dan warrahmah. Tujuan perkawinan tersebut juga secara tidak langsung merepresentasikan bahwa Melayu Sambas sangat erat kaitannya dengan Islam.

Selain itu juga, pantun merupakan salah satu sarana pelajaran dalam hal mengenalkan budaya bangsa Indonesia yang telah lama dilupakan. Pabali Musa sebagaimana yang dikutip oleh Abror, memandang bahwa budaya berpantun pada dasarnya menunjukkan ciri khas dari budaya Suku Melayu dibandingkan dengan Suku lainnya. Ciri khas tersebut menunjukkan asal, bahasa menunjukkan bangsa (keturunan), hilang bahasa lenyaplah bangsa (keturunan), bahasa jiwa bangsa. Hal ini juga berarti menunjukkan budaya pantun dalam tradisi adat istiadat dari Suku Melayu bukan saja pada adat istiadat perkawinan tetapi secara keseluruhan yang telah diciptakan oleh nenek moyang zaman dahulu, maupun budaya yang telah diciptakan zaman sekarang yang mengalami pembaharuan, tetapi tidak terlepas dari nilai-nilai agama yang menaungi dari agama yang dimiliki oleh Suku Melayu yakni agama Islam.

Tulisan ini untuk memberikan legetimasi bahwa budaya pantun dalam tradisi adat istiadat perkawinan yang terjadi pada Sambas pada umumnya dan daerah-daerah atau dikenal dengan Desa yang terletak di Sambas pada khususnya, bahwa pantun dalam tradisi ini masih saja menjadi slogan dalam budaya perkawinan bagi Suku Melayu yang bukan hanya sebagai pesan nasihat untuk kedua pasangan pengantin dalam menempuh kehidupan yang baru yakni keluarga yang sakinah, mawaddah dan warrahmah, tetapi makna pantun menunjukkan asal dari Melayu yang bersangkutan. 


\section{METODE}

Tulisan ini menggunakan metode kepustakaan (library research) yang memusatkan pada budaya pantun dalam acara perkawinan yang diadakan oleh Suku Melayu. Dalam studi kepustakaan ini menggunakan literatur yang berupa buku, catatan, maupun laporan hasil penelitian dan penelitian terdahulu yang berkaitan dengan pantun. Hamilton, dalam bukunya tentang pantun, bahwa merupakan sajak yang menyenangkan bagi para pembaca maupun para pendengar. Namun, budaya nenek moyang tersebut, semakin hari semakin terlupakan, bahkan telah hampir telah hilang budaya pantun tersebut. Kemudian, Ding Choo Ming, bahwa setiap etnik yang ada di Nusantara ini yang ditemukan di berbagai daerah tentang pantun yang juga merupakan unsur dari budaya etnik di setiap daerah. Dalam hal ini, setiap daerah yang berasal dari Suku Melayu mempunyai pantun yang menggambarkan identitas masyarakat yang bersangkutan. Teknik Dalam penulisannya dengan cara mengidentifikasi dari literatur yang diperlukan. Selain itu, penulis juga melakukan dengan pendekatan fenomenologi yakni melihat fenomena yang ada dilapangan daerah Sambas dalam melakukan adat istiadat perkawinan yang dilakukan oleh Suku Melayu.

\section{PEMBAHASAN}

\section{Budaya Pantun Suku Melayu}

Manusia dalam hidupnya tidak terlepas dari budaya yang telah melingkarinya. Budaya ibarat sebuah sangkar yang telah dibuat sendiri oleh manusia dan manusia itu sendiri terjerat oleh sangkar tersebut dan tidak bisa untuk keluar dari sangkar yang telah dibuatnya. Perumpamaan itu mengilhami penulis bahwa budaya adalah kehidupan manusia dan manusia tidak terlepas dari budaya itu sendiri, sehingga manusia dilingkungi oleh budayanya sendiri.

Para ahli antropolog telah banyak mendefinisikan pengertian dari budaya tersebut, misalnya Geertz, manusia tidak terlepas dari budaya, tetapi budaya menyimpan seribu makna yang perlu ditafsirkan. Sementara, ahli antropologi yang paling dikenal di Indonesia yakni Koentjaraningrat. Koentjaraningrat mendefinisikan kebudayaan adalah seluruh dari pikiran manusia, karya, karsa yang bukan berasal dari naluri manusia yang menciptakannya tetapi dari manusia setelah mengalami proses dalam belajar. Oleh karena 
itu, kebudayaan tidak terlepas dari unsur-unsur kebudayaan dan wujud kebudayaan itu sendiri.

Unsur dari kebudayaan yang dikatakan sebagai kebudayaan universal atau kebudayaan yang menyeluruh dikenali di dunia ini. Kebudayaan menurut Kluckhohn terdiri dari tujuh unsur yaitu sistem religi dan upacara keagamaan, sistem organisasi masyarakat, sistem pengetahuan, sistem mata pencaharian hidup, sistem teknologi dan peralatan, bahasa, serta kesenian. Sementara wujud dari kebudayaan. Dalam pandangan Koentjaraningrat terdiri dari tiga wujud kebudayaan yaitu sebagai suatu kompleks dari ide-ide, gagasan, nilai-nilai, norma-norma, peraturan, dan sebagainya. Hasil dari aktivitas kelakuan yang dilakukan manusia dan hasil karya benda manusia yang telah diciptakan oleh manusia itu sendiri.

Manusia adalah bagian dari unsur kebudayaan. Pada tataran ini manusia adalah pencipta budaya yang bernilai positif yang menjadi pedoman dalam kehidupan manusia. Dalam kehidupan Melayu Sambas budaya tersebut diantaranya dikenal sebagai adat istiadat. Pantun merupakan adat istiadat yang melekat erat dalam kehidupan Melayu Sambas. Pada tataran ini pantun digunakan dalam berbagai dimensi kehidupan sosial Melayu Sambas misalnya untuk menyampaikan pesan kepada pengantin dalam memulai hidup berumah tangga.

Pantun adalah satu genre yang sangat disukai oleh masyarakat Melayu. Identias dari pantun bagi Suku Melayu, merupakan kebangkitan dan perkembangan dari Melayu itu sendiri. Pantun berasal dari kata "tun" yang digunakan dalam bahasa Jawa Kuno, artinya tuntut-atuntut. Dalam bahasa Indonesia artinya mengatur, sehingga dibuat kesimpulan menjadi aturan dan susunan. Menurut R.O. Winsted, pantun bukanlah sekedar gubahan kata-kata tetapi mempunyai kandungan makna yang padat, baik menggambarkan tentang percintaan, rindu, dendam maupun dalam acara perkawinan.

Menurut Tuti Andriani, pantun dikenalkan secara meluas dan pembukuannya diterbitkan pertama kalinya pada tahun 1877 oleh W. Bruining di Batavia. Pantun di tahun 1877 dikenal sebagai pantun berkait, karena antara bait pertama dan kedua dan seterusnya mempunyai makna tersendiri. Jumlah barisnya terdiri dari dua baris, empat baris, bahkan delapan baris. Naskah pertama pantun ditemukan di perpustakaan Universitas Leiden dan dari naskah tersebut hanya salinannya, pada bagian depannya tertulis nama R. Univ. Bibliotheek Leiden.

Ding Choo Ming, menggambarkan antara tahun 1899 dan 1940, telah terbit 35 buku yang terdiri dari 11.204 rangkap pantun, syair dan dondang sayang. Secara historis 
dan antropologisnya, Tuti Andriani, menyebutkan bahwa pantun sejak dahulu telah digunakan oleh berbagai elemen masyarakat Melayu seperti pemuka adat dan tokoh masyarakat dalam pidato, pedagang yang menjajakan dagangannya, dan orang yang ingin menyatakan kebahagiaan. Pantun tersebut digunakan berbagai macam adat dalam upacara yang diadakan oleh Suku Melayu, termasuk adat istiadat perkawinan. Pada saat ini penggunaan pantun lebih meluas lagi, pantun sudah menjadi tradisi diberbagai media sosial termasuk facebook, WhatShap, Instagram dan lainnya untuk mengungkapkan perasaan melalui media sosial tersebut tanpa berjumpa dengan pasangannya. Ungkapan perasaan melalui pantun tersebut sehingga pencarian jodoh sudah mulai melalui media sosial dengan hanya melihat pasangan dimedia sosial tersebut, sehingga pencarian jodoh lebih mudah dibandingkan pada zaman dahulu.

Dari perjumpaan tersebut, sehingga menjadi sebuah ikatan yang suci yakni perkawinan yang bukan saja dari Suku Melayu tetapi dari berbagai Suku yang mencari hubungan melalui media sosial tersebut. Namun, walaupun pencarian jodoh sudah mulai berubah, tetapi adat istiadat pantun dalam acara perkawinan yang dilakukan oleh Suku Melayu masih tetap saja sama tanpa mengalami pembaharuan. Dari sisi inilah, kekhasan yang dimiliki oleh Suku Melayu dibandingkan oleh Suku-Suku lainnya.

\section{Adat Istiadat Perkawinan}

Sejak dahulu sampai sekarang Melayu hidup berpegang teguh dengan adat. Dalam bahasa Arab, adat disebut 'adah atau dalam istilah bahasa Indonesia adalah kebiasaan. Menurut pemikiran dari Suku Melayu, adat harus dipegang teguh agar tidak punah oleh perubahan zaman sehingga adat dijadikan simbol oleh Suku Melayu. Bunyi pesan simbol dari adat yang dipegang oleh Suku Melayu sebagaimana yang disebutkan Abror, adalah "hidup dikandung adat, mati dikandung tanah", atau dalam pepatah adat yang lain "biar mati anak, asalkan jangan mati adat". Selain itu, dalam gurindam dua belas yang dituturkan oleh Raja Ali Haji bahwa tak kan hilang Melayu di telan bumi. Menurut Surtina, pepatah adat tersebut menunjukkan bahwa bagi Suku Melayu sangat menjunjung tinggi adat istiadatnya.

Penggunaan pantun dalam adat istiadat Melayu Sambas diantaranya adalah dalam acara perkawinan. Fungsi pantun dalam acara perkawinan tersebut untuk menyampaikan nilai pesan bagi kedua pasangan pengantin. Bahkan, adat dari Pantun Suku Melayu telah menjadi simbol dari khasnya perilaku Suku Melayu dalam acara perkawinan. Selain itu, 
nilai-nilai adat yang ada pada Suku Melayu tidak terlepas dari adat Islam yang terungkap dalam pantun dibawah ini.

Berguna hidup karena beradat,

Adat lembaga jadi pakaian,

Sempurna hidup karena syahadat,

Syahadat dijaga pengukuh iman.

Adat orang berjalan malam,

Adat suluh jadi pedoman,

Adat orang beragama Islam

Adat petunjuk menerangi iman.

Dilihat dari pesan pantun tersebut yang sudah tertanam dalam jiwa Suku Melayu, bahwa Melayu adalah simbol dari adat yang bernafaskan Islam, yang bukan saja adat dari perkawinan tetapi adat-adat yang lainpun tidak terlepas dari nilai Islam. Menurut Muhammad Takari bin Jilin Syahrial, menyebutkan bahwa adat yang dimiliki oleh Suku Melayu tidak terlepas dari nilai-nilai Islam yang merupakan sinonim dari kebudayaan Suku Melayu itu sendiri. Bagi Suku Melayu, adat adalah sejumlah warisan tradisi yang diturunkan sejak turun temurun dan telah menjadi hukum dan peraturan yang harus dipatuhi oleh masyarakat Melayu. Istilah adat banyak dimiliki oleh suku yang lain, oleh karena itu Suku Melayu memberi nama dari adat tersebut adalah adat istiadat. Adat istiadat yang dirumuskan oleh Suku Melayu merupakan peraturan dalam melakukan sesuatu yang tidak bertentangan dengan norma yang ada pada Suku Melayu sehingga diterima oleh adat. Agar pewarisan adat istiadat ini sudah dikenal bahkan dikenali oleh Suku yang lain, sehingga Suku Melayu merumuskan empat ciri khas dari adatnya itu sendiri diantaranya adat yang sebenar adat, adat yang diadatkan, adat yang teradat, dan adat istiadat.

Dari keempat ciri khas tersebut, upacara apapun, termasuk perkawinan yang dimiliki oleh Suku Melayu tidak terlepas dari sumber tersebut. Pada tataran ini setiap upacara yang dilakukan selalu diiringi dengan ritual khusus yang setiap dari ritual tersebut mengandung makna yang pengertiannya hanya diketahui oleh Suku Melayu tersendiri, misalnya dalam ritual berinai, bekasai, balik tikar, malam terabak dan ritualritual lainnya dalam acara perkawinan.

Menurut Akmal, kebanyakan pantun yang dilakukan oleh Suku Melayu pada umumnya dalam adat istiadat perkawinan berisi petuah, nasihat, atau tunjuk ajar yang 
berguna bagi pasangan pengantin. Bahkan, pantun yang merupakan warisan tradisi telah menjadi alat komunikasi bagi kedua pengantin. Bagi acara adat istiadat perkawinan pantun bukan hanya saja sebagai komunikasi dalam berbahasa tetapi pantun dijadikan sebagai simbol dalam menyampaikan pesan-pesan khas bagi kedua belah pihak (pihak lelaki dan wanita).

Tuti Andriani, dalam beberapa acara adat istiadat, pantun sering dilantunkan dengan indah dan berirama dalam sebuah acara sebagai khas dari nuansa Melayu. Dalam konteks tersebut pantun mengalami perubahan sesuai dengan zamannya. Menurut Zahir Ahmad, jika ditinjau berdasarkan asal sejarah pantun itu adalah tidak terlepas dari semangat kerjasama dan gotong royong, yang bukan saja dilihat dari bertani, berkebun, tetapi dalam acara perkawinan pun masih adanya gotong royong. Seperti dalam acara adat istiadat pernikahan yang dilakukan oleh Suku Melayu yang ada di Sambas yang masih saja membawa nilai-nilai dari pantun tersebut walaupun bahasa pantunnya sudah mengalami perubahan sesuai dengan zamannya.

\section{Makna Pantun Adat Istiadat Perkawinan Suku Melayu di Sambas}

Pantun selama ini sudah terlupakan oleh generasi-generasi penerus banga Indonesia, khususnya bangsa dari Suku Melayu. Padahal, pantun di zaman dahulu menjadi identitas bagi bangsa Melayu yang telah banyak dikaji oleh pakar antropologi. Dalam budaya Sambas, pantun memainkan peranan yang sangat penting dalam adat istiadat perkawinan Melayu Sambas. Pantun dalam acara adat istiadat perkawinan yang dilakukan di Sambas bukan saja untuk melengkapi acara tetapi sebagai menyampaikan hajat dan pesan yang baik terhadap kedua pasangan dalam mendirikan rumah tangga. Urgensi pantun dalam adat istiadat perkawinan Melayu Sambas tidak hanya bertujuan untuk membangun sebuah keluarga yang bahagia, tetapi juga sebagai pewarisan budaya, nilai rasa dan akhlak kepada generasi selanjutnya. Namun, proses pewarisan saat ini mengalami beberapa permasalahan serius yaitu kurangnya perhatian masyarakat tentang adat istiadat Melayu sehingga warisan leluhur ini yang perlu mendapatkan sorotan oleh generasi setelahnya tidak dihiraukan, sehingga banyak remaja yang terjadi penyimpangan-penyimpangan atau kenakalan remaja. Oleh karena itu menurut Sudarsono, pantun bukan saja sebagai asumsi bagi kedua pesan pasangan pengantin tetapi dapat juga sebagai untuk mengantisipasi bagi adanya kenakalan remaja. Warisan nilai dari pantun ini yang diajarkan kepada generasi anak muda dengan sedini mungkin dapat mengantisipasi dari kenakalan remaja yang dilakukan karena kurangnya 
pemahaman tentang agama yang bisa saja melalui pantun maupun dengan media yang lainnya.

Pantun merupakan media yang digunakan dalam berkomunikasi dalam masyarakat, baik golongan muda maupun yang tua. Golongan muda untuk mengungkapkan rasa cinta, curhat, sementara yang tua dalam acara adat-istiadat, misalnya nasihat, perkawinan. Penggunaan pantun dalam adat istiadat perkawinan Melayu Sambas diantaranya dalam acara antar barang. Bahkan, hampir setiap Melayu yang tinggal diberbagai daerah tidak terlepas dari antar barang, seperti halnya masyarakat Melayu Minang Kabau, sebelum melakukan antar barang, maka melakukan "Minanti Tando" atau pihak lelaki datang ke rumah pihak perempuan untuk menyampaikan maksud kedatangan pihak lelaki. Acara antar barang yang dilakukan oleh Suku Melayu di Sambas adalah prosesi pihak lelaki mengantar barang kepada pihak perempuan yang nantinya barang tersebut akan dibacakan satu persatu oleh pihak perempuan apabila barang tersebut sudah diserahkan terlebih dahulu oleh pihak lelaki. Dalam acara ini, sebelum barang-barang ini diserahkan, terlebih dahulu pihak lelaki berpantun untuk memberi tahu rombongan yang datang dari pihak lelaki semuanya adalah keluarga atau sanak saudara. Bunyi pantunnya sebagai berikut:

Kacang bukan sembarang kacang

Kacang melilik diatas intare

Kamek datang bukan sembarang datang

Kamek datang membawa sanak saudare.

Sementara balasan dari pihak perempuan yang mewakili dengan membalas pantun dari pihak lelaki dengan berbunyi:

Buah kacang diambek nakdare

Untuk tambahan lauk pada hari yang pertame

Biar yang datang dari pihak lelaki bukan sanak saudare

Berat telapak tangan, nyiruk kamek tadahkan, kamek terimak semua.

Makna nilai dari pantun ini adalah memberi pesan kepada pihak perempuan

bahwa walaupun yang datang bukan dari saudara atau keluarga pihak lelaki, dengan senang hati bagi pihak perempuan untuk menerimanya. Nilai-nilai inilah yang selalu melekat dalam tradisi Suku Melayu dalam acara adat istiadat perkawinan. Begitu juga halnya bagi pasangan kedua pengantin diberikan nasihat yang baik oleh pihak lelaki 
dan pihak perempuan yang telah ditunjuk sebagai penyampaian hajat oleh kedua belah pihak. Pesan yang terdapat dalan pantun tersebut adalah untuk menyiapkan bekal kepada kedua pasangan agar menjadi keluarga sakinah, mawaddah dan warrahmah. Bunyi pantunnya adalah sebagai berikut:

\section{Pergi berlayar dengan ulama}

\section{Tidak lupa membawa timah}

Hari itok kitak udah hidup bersama

Jagalah bini agar menjadi keluarga yang sakinah, mawaddah dan warrahmah.

Pantun merupakan identitas warisan budaya yang perlu dijaga oleh bangsa Indonesia saat ini. Pantun menggambarkan juga tentang kehidupan masyarakat. Masyarakat yang hidup di zaman era informasi, masalah identitas yang berkaitan dengan pantun semakin terabaikan. Bahkan jarang sekali, masyarakat berpantun dalam kehidupan sehari-hari seperti zaman nenek moyang, seperti bertamu, menyapa dan lain sebagainya, sehingga pantun sering digunakan dalam acara perkawinan, tetapi hanya sebagian masyarakat yang bisa berpantun, karena kebanyakan sudah meninggal dunia dan tidak diturunkan kepada anak-anaknya, cucunya maupun orang lain.

Abror, yang meneliti pantun dengan kajian lapangan dalam kehidupan masyarakat Melayu Pontianak di Kelurahan Dalam Bugis dan Banjar Serasan, Kecamatan Pontianak Timur, Kotamadya Pontianak, Kalimantan Barat. Dalam urgensi penelitian Abror, bahwa pantun yang merupakan warisan tradisi semakin lama semakin berkurang dan tradisi ini telah lama kehilangan pendukungnya dan yang masih hapal dengan pantun umumnya masyarakat yang sudah tua.

Keindahan kata dalam pantun memperlihatkan pemikiran dan falsafah Melayu tradisional yang tinggi, asli dan mempunyai nilai seni. Dalam buku Shabri Shaleh Anwar yang berjudul "Membangun kerohanian melalui syair Pantun" dalam cover depan bukunya menggambarkan makna nilai pantun seperti "seni yang indah lagi lembut, menusuk qalbu orang yang santun, isinya sarat makna yang patut, membangun rohani dari syair dan pantun". Bagi Suku Melayu, makna pantun atau kandungan dalam bait-bait pantun tidak merasa sulit mereka memahaminya, karena mereka sering mendengar pantun dan berpantun, sedangkan bagi non Melayu, tidaklah semudah memahami pantun dari suku Melayu, karena untuk mengetahui pantun dari Melayu, maka terlebih dahulu mengetahui pengetahuan mengenai masyarakat dan kebudayaan Melayu, baik yang 
berkaitan dengan simbol maupun bahasanya. Perbedaan makna pantun bagi suku Melayu dengan non Melayu tidak terlepas dari ciri khas yang dalam sejarahnya, pantun mewarnai kehidupan suku Melayu.

\section{KESIMPULAN}

Berdasarkan analisis di atas dapat disimpulkan bahwa sejak dahulu hingga sekarang pantun sudah menjadi tradisi dalam upacara perkawinan Melayu Sambas. Penggunaan pantun dalam adat istiadat perkawinan Melayu Sambas adalah sebagai media penyampaian nasehat dan petuah bagi mempelai dalam menjalani kehidupan berumah tangga. Hasil peneltian berdasarkan literatur dan pengalaman penulis sewaktu memperhatikan prosesi adat istiadat perkawinan adalah; Pertama., Pantun menggambarkan identitas bagi Suku Melayu. Kedua, Pada era masa dahulu, pantun mengalami sistem keemasan, sehingga banyak peneliti antropolog dari Barat meneliti pantun dari Suku Melayu yang ada di Indonesia. Ketiga, dalam acara adat istiadat perkawinan yang diadakan oleh Suku Melayu, maka budaya berbalas pantun masih tetap saja lestari sampai saat ini. Akan tetapi, bagi pihak lelaki dan pihak perempuan masingmasing menyiapkan masyarakat tua untuk saling membalas pantun pada saat acara pernikahan diadakan. Hal yang mengkwatirkan bagi penulis, dalam acara pernikahan tersebut, hanya yang berbalas pantun adalah masyarat tua sehingga dalam penyebutan vokal hurufnya kurang jelas. Seandainya, masyarakat muda tidak belajar pantun kepada yang tua, maka punahlah sudah budaya pantun bagi Suku Melayu, sehingga pantun nantinya hanyalah sebatas simbol yang telah terlupakan jasa-jasanya bagi Suku Melayu pada zaman dahulu.

\section{DAFTAR PUSTAKA}

A. W. Hamilton. Malay Pantuns. Sydney, N.S.W: Australasian Publishing Co. Pty. Ltd, 2004.

Abror, Abd Rachman. Pantun Melayu, Titik Temu Islam dan Budaya Lokal Nusantara. Yogyakarta: Lkis Pelangi Aksara, 2009.

Abror, Abdurahman. "Nilai Budi Dan Keislaman Dalam Pantun Melayu Pontianak." Jurnal Khatulistiwa - Journal Of Islamic Studies 1, no. 2 (2011): 177-200.

Ahmad, Zahir. "Pantun Melayu Sebagai Manifestasi Sosio budaya dan Pensejarahan Melayu.” Pengajian Melayu 16, no. 1 (2015): 241-54. 
Akmal. "Kebudayaan Melayu Riau (Pantun, Syair, Gurindam).” Risalah 26, no. 4 (2015): $159-65$.

Andriani, Tuti. "Pantun Dalam Kehidupan Melayu (Pendekatan Historis dan Antropologis)." Sosial Budaya 9, no. 2 (2012): 195-211.

Anwar, Shabri Shaleh. Membangun Kerohanian Melalui Syair \& Pantun. Indragiri TM, 2016.

Aslan. "Nilai-Nilai Kearifan Lokal Dalam Budaya Pantang Larang Suku Melayu Sambas" 16, no. 1 (2017): 35-44.

Asmal, Erizal Gani, dan Abdurrahman. "Struktur Dan Fungsi Pantun Managua Pada Upacara Pernikahan Di Kota Baru Kecamatan Bao Utara Kabupaten Pasaman.” Pendidikan Bahasa dan Sastra Indonesia 1, no. 1 (2012): 600-686.

Cerdas, Redaksi Indonesia. Peribahasa \& Pantun Indonesia. Indonesia: Galangpress Group, 2009.

Diing Choo Ming. "That Mighty Pantun River and Its Tributaries." Wacana 12, no. 1 (2010): 115-30.

Fandi, Leo, Agustina, dan Nurizzati. "Struktur Dan Fungsi Pantun Minangkabau Dalam Masyarakat Pasa Lamo, Pulau Punjung, Dharmasraya.” Pendidikan Bahasa dan Sastra Indonesia 1, no. 1 (2012): 278-86.

Gani, Erizal. "Kajian Terhadap Landasan Filosofi Pantung Minangkabau." Bahasa dan Seni 10, no. 1 (2009): 1-10.

Gawa, John. Kebijakan dalam 1001 pantun. Indonesia: Penerbit Buku Kompas, 2007.

Geertz, Clifford. The Interpretation Of Cultures. New York: Basic Books, Inc., Publisher, 1973.

Karim, Ab. Razak Ab., dan Nurul Ain Alizuddin. "Analisis Ayat Majmuk Pancangan Bahasa Melayu Dalam Pantun Melayu.” Pengajian Melayu 26 (2015): 1-28.

Ming, Ding Choo. "The Malaysian Baba Pantun Database” 22 (2004): 159-65.

Mujiburrahman. Bercermin Ke Barat: Pendidikan Islam Antara Ajaran dan Kenyataan. Cetakan Pertama. Banjarmasin: Jendela, 2013.

Overbeck, H. "The Malay Pantun.” Of the Straits Branch of the Royal Asiactic 85 (t.t.): $4-28$. 
Sudarsono. Kenakalan Remaja: Prevensi, Rehabilitasi dan Resosialisasi. Jakarta: Rineka Cipta, 2008.

Suhartini, Andewi. "Menggagas Pendidikan Masa Depan." Penelitian Pendidikan Agama dan Keagamaan 1, no. 2 (2003): 102-7.

Supartono. Ilmu Budaya Dasar. Perpustakaan Nasional: Katalog Dalam Terbitan (KDT), 2009.

Surtina. "Nilai Budaya dan Nilai Agama Pada Upacara Pernikahan Adat Melayu Desa Benan Kecamatan Senayang Kabupaten Lingga Provinsi Kepulauan Riau.” Skripsi, Fakultas Dan Keguruan Ilmu Pendidikan Maritim Raja Ali Haji, 2014.

Syahrial, Muhammad Takari bin Jilin. "Adat Dalam Peradaban Melayu." Laporan Penelitian. Fakultas Ilmu Budaya: Universitas Sumatera Utara, 2015.

Sztompka, Piotr. Sosiologi Perubahan Sosial, terj. Alimandan. Cetakan ke 7. Jakarta: Prenadamedia Group, 2014.

Tarigan, Dra Nismawati. Bibliografi Beranotasi: Hasil Penelitian Balai Pelestarian Sejarah dan Nilai Tradisional Tanjungpinang. Indonesia: Direktorat Jenderal Kebudayaan, 2009.

Tedjowirawan, Anung. "Persejajaran Unsur-Unsur Autochton Dalam Cerita Panji Angreni Dengan Cerita Pantun Mungdinglaya Dikusumah.” Humaniora 16, no. 3 (2004): 290-302.

Thomas, Phillip L. "Syair and pantun prosody.” Indonesia, no. 27 (1979): 51-63.

Vartinya, Varti Sevarti. Pantun 100\% Gokil. Yogyakarta: Media Pressindo, 2010.

Waridah, Ernawati. Kumpulan Majas, Pantun, dan Peribahasa plus Kesusastraan Indonesia. Bandung: Ruang Kata, 2014.

Yatim, Rais. Pantun \& Bahasa Indah: Jendela Budaya Melayu. 2 ed. Kuala Lumpur: Endowment Publications, 2014.

Yenti, Ermi, Hamidin, dan Amril Amir. "Pantun Bajawek Dalam Acara Mananti Tando Di Binjai Kecamatan Tigo Nagari Kabupaten Pasaman: Telaah Struktur dan Nilai Pendidikan.” Pendidikan Bahasa dan Sastra Indonesia 1, no. 1 (2012): $628-38$. 